\title{
AS NOVAS METODOLOGIAS DE ENSINO E A FORMAÇÃO DOCENTE
}

\author{
MARIA DEUCENY DA SILVA LOPES BRAVO PINHEIRO ${ }^{1}$, ALFREDO \\ BRAVO MARQUES PINHEIRO ${ }^{2}$.
}

\begin{abstract}
${ }^{1}$ Doutora em Ciências da Educação pela Faculdade de Psicologia e de Ciências da Educação da Universidade de Coimbra, Professora da FACCACI, FDCI e Faculdade América, em Cachoeiro de Itapemirim e nos cursos de pós-graduação da região sul do Espírito Santo. deuceny @ yahoo.com.br.

2 Pós-doutorando em Ciências da Educação na Faculdade de Psicologia e Ciências da Educação da Universidade de Coimbra, Professor da Faculdade de Tecnologia de Cachoeiro de Itapemirim (FACI) e nos cursos de pós-graduação da região sul do Espírito Santo. alfredobravo1@ yahoo.com.br.
\end{abstract}

\section{RESUMO}

A contemporaneidade nos invoca para um olhar diferenciado para a escola, exigindo novas concepções desse espaço e do processo educativo, acompanhadas por fundamentos teóricos, desenvolvidas por intelectuais que lutam por uma política pública que ultrapasse o discurso e que possibilitem conceber esse outro formato de sistema educativo que vem sendo desenhado. Buscam, com isso, fortalecer não somente o discurso, mas a prática para uma educação mais sustentável. Nesse contexto, o presente artigo faz uma reflexão sobre a configuração da escola atual, destacando a necessidade de novas metodologias de ensino e de um projeto educativo arrojado, com num sólido compromisso entre os distintos atores que compõem o território em que a escola está inserida. Finaliza fazendo uma reflexão das teorias pedagógicas apresentadas por Bertran; Valois (1994), sobre projeto educativo e nos estudos de Garcia (1992, 1999), Anastasiou; Alves (2004); Eraut (1995); Ferry (1987); Perrenoud (2000, 2002) e Zeichner (1983) sobre a docência e a formação docente. Pautado nesses autores, destacamos a importância de o professor começar a (re)pensar em suas próprias ações, em suas práticas no cotidiano em sala de aula, enfatizando o papel da formação continuada para seu aprimoramento profissional. Esperamos que o presente estudo suscite reflexões que colaborem com a construção dos projetos educativos locais e para a formação docente, com metodologias que aproximem mais o discurso da prática docente.

Palavras-chave: Projeto Educativo; Teorias Pedagógicas; Metodologias de Ensino; Formação Docente.

\section{NEW TEACHING METHODOLOGIES AND TEACHING TRAINING}

\section{ABSTRACT}


Contemporaneity calls us to a different look at the school, demanding new conceptions of this space and of the educational process, accompanied by theoretical foundations, developed by intellectuals who fight for a public policy that goes beyond the discourse, and that make it possible to conceive this other system format educational model that has been designed. With this, they seek to strengthen not only the discourse, but the practice for a more sustainable education. In this context, this article reflects on the configuration of the current school, highlighting the need for new teaching methodologies and a bold educational project, with a solid commitment between the different actors that make up the territory where the school is inserted. It ends by reflecting on the pedagogical theories presented by Bertran; Valois (1994), on educational project and in the studies of Garcia (1992, 1999), Anastasiou; Alves (2004); Eraut (1995); Ferry (1987); Perrenoud (2000, 2002) and Zeichner (1983) on teaching and training teacher. Based on these authors, we highlight the importance of the teacher to start (re) thinking about his own actions, his daily practices in the classroom, emphasizing the role of continuing education for his professional improvement. We hope that this study will give rise to reflections that collaborate with the construction of local educational projects and for teacher training, with methodologies that bring the discourse closer to teaching practice.

Keywords: Educational Project; Pedagogical Theories; Teaching methodologies; Teacher Education.

\section{INTRODUÇÃO}

Com amplo significado dialético, a escola faz parte da vida crianças, dos jovens e dos adultos. Com um cotidiano diversificado, institucionalmente, cabe a ela educar sistemicamente os indivíduos nas diferentes idades da sua formação. Um conceito formal para uma instituição que, ao longo da história da educação, vem apresentando diferentes configurações temporais e espaciais e cotidianos específicos no processo de escolarização dos diferentes povos, servindo a um tempo determinado e configurandose de características de determinado tempo (FERREIRA, 2005).

As novas demandas vêm asseverando à escola como instituição especializada na socialização e na educação das crianças, exigindo dela novas metodologias, notadamente porque ela é muito mais complexa daquilo que é enunciado nos diversos discursos e a escolarização é um processo muito mais abrangente do que a mera aquisição de conhecimentos.

O desenvolvimento das tecnologias encurtou as distâncias, facilitou as relações sociais e rompeu com as barreiras físicas e geográficas, construindo e reconstruindo conceitos. $\mathrm{O}$ acesso rápido à informação põe em xeque as aulas tradicionais, voltadas meramente à reprodução de conhecimento. Portanto, cabe ao educador o grande desafio 
de acompanhar o desenvolvimento dos estudantes nessa nova experiência, com práticas pedagógicas mais dinâmicas, que promovam uma maior participação e despertem neles sentimentos e atitudes necessárias à construção de uma vivência coletiva.

Nesse sentido, é preciso habilitar o espaço escolar como espaço de vida, de aprendizagem holística e permanente, que promova e desenvolva nos estudantes valores éticos e de responsabilidade. É nesse contexto que o presente artigo faz uma reflexão teórica sobre as novas demandas desse novo cenário, que requer uma concepção mais embasada de educação e dos projetos educativos. Com as teorias pedagógicas apresentadas por Bertran; Valois (1994), Garcia (1992,1999), Anastasiou; Alves (2004) Anastasiou; Alves (2004); Eraut (1995); Ferry (1987); Perrenoud (2000, 2002) e Zeichner (1983), refletimos sobre a necessidade de metodologias mais participativas que possam contribuir para que a comunidade escolar requalifique suas práticas, encontrando referências teóricas e metodologias mais adequadas que possibilitem o envolvimento e a participação efetiva de todos os seus membros no processo educativo.

\section{TEORIAS PEDAgógICAS: FUNDAMENTOS PARA UMA POLÍtica EDUCATIVA MAIS ARTICULADA E INOVADORA.}

Na década de 1990, o Paradigma do Desenvolvimento Humano, proposto pelo Programa das Nações Unidas para o Desenvolvimento (PNUD) e a publicação do Relatório Jacques Delors (UNESCO, 1996), trouxe à tona o debate sobre a necessidade de uma educação plena, que considerasse o ser humano em sua integralidade de forma que permitisse a todos, de maneira equitativa, desenvolver talentos e potencialidades criativas que possibilitassem assumir sua própria responsabilidade de realizar seu projeto pessoal. Porque vivemos num mundo marcado por muitas desigualdades sociais, há que se procurar encontrar formas de superar os problemas educativos que daí resultam e, com as soluções encontradas, diminuir as clivagens derivadas da condição social das pessoas. Nesse sentido, importa dar especial atenção à dimensão social num projeto educativo, tanto no que toca à igualdade de oportunidades como no que diz respeito à partilha de referenciais socioculturais, de modo que todos sejam capazes de promover o sentimento de pertencer a uma humanidade comum, compartilhando valores, responsabilidades, empatia e que possam colaborar, através de uma atuação 
efetiva e responsável, em diferentes escalas e contextos, na construção de um mundo mais pacífico e sustentável (UNESCO, 2016).

Tomando por base esses fundamentos, devemos tirar deles mais consequências para uma política educativa do que tem sido feito, mesmo considerando a produção acadêmica. Tomada na sua amplitude conceitual, ela exige redefinir o modo de conceber o sistema educativo. Em geral, podemos dizer que se trata de trazer para a política educativa práticas que estão ao alcance de famílias bem situadas na sociedade. Ou seja, há que ampliar os dispositivos necessários para que toda a população tenha idênticas possibilidades de desenvolvimento. Isso implica considerar outras instituições para além da escola, outros atores para além dos professores, outras articulações disciplinares, outras opções educativas. A formação da pessoa não deve estar sujeita a uma só forma, ao privilégio de alguns aspectos, a uma só instituição

Nesse contexto, os questionamentos acerca do papel da escola e os rumos da educação contemporânea levam-nos em busca de auxílio em paradigmas que fundamentam as possibilidades de se avançar na construção da sociedade que desejamos e que julgamos ser possível construir e em mudanças educativas que sejam capazes de contribuir para um desenvolvimento sustentado. O paradigma racional da educação, decorrente da sociedade industrial, depara-se com a necessidade cada vez maior de alternativas para um desenvolvimento mais humano e menos centrado na riqueza das economias, que esteja atento às necessidades básicas e ao bem-estar coletivo (PNUD, 2015). Contudo, um sistema educativo não pode ser pensado como a promessa do paraíso. Tem de ser equacionado a partir da leitura que fazemos das possibilidades de concretizar uma educação em função das condições materiais, sociais e culturais disponíveis ou viáveis. Por outro lado, tem de se pensar a educação, considerando pressupostos em que deve assentar a sua acentuação e que podem ser os considerados por Bertrand (2001), quando procurou arrumar as teorias pedagógicas contemporâneas.

As teorias pedagógicas apresentadas por Bertrand (2001) estão agrupadas num esquema tripolar, sobre o qual elaboramos um modelo para melhor compreendermos e explicitarmos o que está em causa na definição de uma política de educação (Figura1). 
Figura 1- Configuração Tripolar

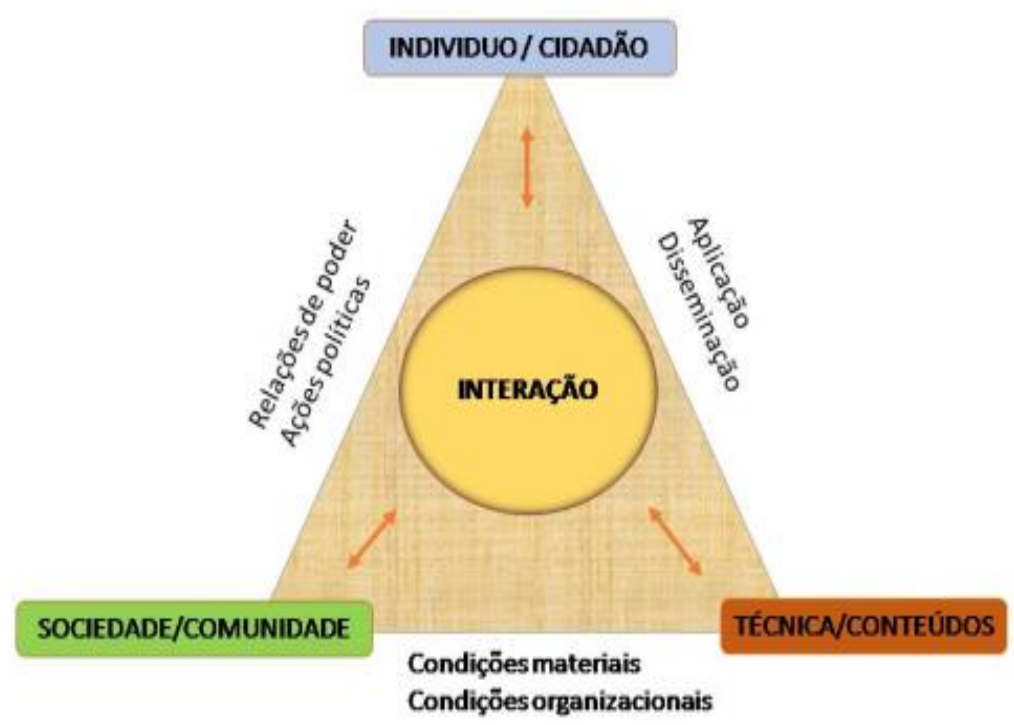

Fonte: Adaptado de Bertrand e Valois (1994).

Como é evidente, um esquema é uma simplificação da realidade e isso deve ser aqui entendido como tentativa de tornar claro que há opções a fazer e que elas decorrem da forma como vemos a pessoa diante de um contexto antropológico sujeito a condicionantes físicas, materiais, sociopolíticas e culturais. Ou seja, como se equaciona a direção a dar à educação em função de visões de mundo, de possibilidades e de caminho coletivo, de convicções mais ou menos otimistas sobre as pessoas.

Assim, ampliando o esquema triangular de Bertrand, temos no vértice superior o indivíduo, o cidadão. Bertrand (2001) agrupava em torno do sujeito as teorias que dão prioridade aos aspetos espiritualistas e personalistas. A corrente espiritualista assenta na relação transcendental e espiritual entre o homem e o Universo. Nela, a educação não é segmentada, busca a unidade, através da escuta, da receptividade, da intuição, do amor e da sinergia espiritual. Por sua vez, a corrente personalista está focada na dinâmica interna da pessoa, em suas necessidades, aspirações, desejos e energia. Também valoriza a relação entre as pessoas, a compreensão do outro. Nessa concepção, o professor desempenha o papel de facilitador da aprendizagem e o processo educativo se 
apresenta como um conjunto estruturado e dinâmico de interações entre o educando e o meio educativo A educação só faz sentido porque há um coletivo humano.

Ainda segundo este autor, a educação existe porque se reconhece pertinência à passagem de conhecimento, nomeadamente o que é legado pela geração anterior. Mas, também existe porque deverá proporcionar uma formação capaz de assegurar um futuro melhor a uma sociedade. Isso explica que, no vértice esquerdo do triângulo apresentado, apareça a sociedade, a comunidade, procurando traduzir nisso, as teorias que acentuam a função social da educação. Aqui se incluem, portanto, as teorias sociais que abordam o papel da educação na transformação da sociedade e da cultura e que defendem uma escola comprometida com as mudanças necessárias na comunidade, para que esta seja mais democrática e inclusiva e aquela se articule mais com as vivências do meio em que está inserida.

Com esse enfoque, a pedagogia se volta para a valorização das experiências do indivíduo com o seu meio, que envolvem relações pessoais, organizacionais, locais e centros de interesse, ações estruturadas, caracterizadas pela ação política, com suas ideologias, símbolos e valores, cabendo à escola, nesse contexto, a função de reproduzir, adaptar ou transformar a sociedade (BERTRAND; VALOIS, 1994).

A movimentação do indivíduo na sociedade confronta-se com relações de poder, caracterizadas pela ação política que Arendt (2007) classifica como um gesto coletivo, que, sem a participação efetiva dos cidadãos, representa controle e submissão. Considerando que as relações de poder pautam-se no princípio de liberdade, para garantir a manutenção da democracia (BOBBIO, 1988), a ação política não deve se limitar a um grupo restrito e privilegiado, porque a política tem sua base na pluralidade humana e trata da convivência e da forma organizada da sociedade em alcançar objetivos comuns.

Todavia, a sociedade é uma entidade abstrata que envolve interesses e grupos diversificados. Como diz Dewey (2004), não existe o público em singular, mas públicos, grupos de diversos matizes que interatuam entre si e vão descobrindo interesses comuns e definindo formas de ação através de organizações diversas. Por isso, é preciso formar cidadãos capazes de decodificar os reais interesses que se impõem nas ações privadas e estatais e de tomarem consciência que só a participação de cada um pode garantir que as suas necessidades e interesses encontrem de algum modo respostas 
condizentes. Significa que a ação política não tem um espaço definido à priori. Ele tem de ser estabelecido a partir da capacidade de participação das pessoas que, por sua vez, dependem de estar preparadas para equacionarem os seus problemas, organizarem-se e desenvolverem as ações tidas por convenientes.

Portanto, a participação consciente é uma componente importante para a prática democrática. A ação política só faz sentido enquanto uma ação conjunta, envolvendo o sujeito e seu coletivo, notadamente porque as mudanças políticas expressivas passam pela coesão social, pelo resgate do sentimento de pertença, pela conexão e visão comum que existe entre os indivíduos e as comunidades dentro de uma sociedade e por uma cultura de diálogo, através do exercício da palavra (HANSOTTE, 2005), com vistas a garantir o bem-estar coletivo. Urge romper com o conformismo que caracteriza a sociedade moderna (ARENDT, 2007) com ações que possibilitem sair do espaço de aparência, de despersonalização da vida pública, para enunciar e negociar ações mais desejáveis para o futuro, numa perspectiva de mundialização, com uma educação voltada para o desenvolvimento de uma cidadania global, que prepare as pessoas para assumirem seu papel de cidadãos, promovendo mudanças de posturas que gerem iniciativas para a construção de um mundo mais justo e solidário.

No terceiro vértice está o saber técnico, o conhecimento, a cultura escrita, a valorização dos conteúdos a ensinar. Com uma estrutura sistêmica, essa vertente é marcada por uma organização lógica de recursos e meios que direciona e ordena o ensino com o auxílio das tecnologias adequadas. As teorias tecnológicas voltam sua atenção para as condições de ensino e consideram ser necessário avançar com os processos de comunicação pedagógica de forma a aperfeiçoar a aprendizagem e solucionar os problemas diagnosticados.

Assim, a tecnologia da educação assume importante papel entre a teoria e a prática docente, nomeadamente por ser transdisciplinar, aplicar-se às diversas áreas do conhecimento e fazer parte do contexto das gerações implicadas. Dessa forma, entre a técnica e o indivíduo, encontramos um conjunto de suportes para uma aplicação sistemática dos conhecimentos científicos de modo que sejam capazes de resolver problemas. Contudo, entre o conhecimento, a técnica e a pessoa, há relações bionívocas, umas mais instrumentais e outras mais substanciais. 
$\mathrm{O}$ conhecimento e a técnica tendem a ser utilizados para responder às necessidades identificadas, mas, por outro lado, a disseminação do conhecimento favorece o desenvolvimento da pessoa, a sua capacidade de pensar e agir com mais consistência. Nessa lógica, o conhecimento e a técnica devem ser perspectivados como susceptíveis de originarem novos entendimentos de mundo, de desencadearem novas formas de se pensar e organizar as relações, de relançarem transformações societais.

Os três vértices enquadram o campo das interações entre sujeito, sociedade e conteúdos. Ao privilegiar a interação entre o sujeito e a sociedade, as teorias interacionistas relevam valores éticos e morais que constituem requisitos básicos para o saber ser e saber viver com o outro, expressando a interdependência entre a educação e a sociedade, a escola e a comunidade em que se insere, a reflexão e a prática pedagógica.

A abordagem sistêmica está associada a uma preocupação com problemas decorrentes das estruturas sociais, políticas e culturais e favorece o aparecimento de novos valores, baseados na participação, descentralização, cooperação, trabalho criativo, lógica global, pensamento inventivo, respeito pelo outro, enfim, pelo convívio, preparando a educação para o futuro através da aquisição de conhecimentos essenciais que possibilitem que o saber adquirido colabore para a transformação da sociedade e da cultura.

As teorias psicognitivas que explicam o desenvolvimento do conhecimento por interação entre sujeito-objeto, em especial através da construção de significados, associados à apropriação do mundo por cada indivíduo, resultante das suas experiências (PIAGET, 1970), e as teorias sociocognitivas que valorizam o papel mediador das interações sociais, para o desenvolvimento das capacidades de cada pessoa, têm sido centrais nas formulações da relação pedagógica dos últimos decênios. De acordo com Vigostsky (1979), o indivíduo constrói os esquemas de pensamento e faz a apropriação da realidade, assim como os referentes de comportamento, a partir da interação com os outros e, é nessa relação, que podem ser delineados os valores éticos e morais que regulam a convivência, assim como a maturidade da consciência social. Nessa linha, o conhecimento é sempre objeto de intercâmbio social e a tarefa do sujeito é mais de reconstrução que de construção. O novo não surge do vazio nem no vazio. 
Para Vygotsky (1979), a afetividade ocupa papel importante no processo de formação de conceitos, notadamente porque as relações com o outro tomam um sentido afetivo, determinando a qualidade daquilo que está sendo internalizado. O convívio com o outro possibilita estabelecer uma rede de contatos e de formação de novos conceitos e, nesse caso, a intervenção escolar apresenta-se como promotora do agir coletivo. Nesse sentido, considerando que a aprendizagem não acontece de maneira isolada, devemos considerar a dinamicidade da natureza humana e sua densidade antropológica para despertar no indivíduo a vocação humana para a transcendência, que fortaleça os sentimentos de pertença, estreite os laços sociais e desenvolva valores, comportamentos e atitudes de vinculação ética, de respeito e de sensibilidade que fomentem práticas sociais, econômicas e políticas de sustentabilidade.

Considerando a complementariedade de perspectivas, amplamente defendida por Dennick (2015), podemos conceber a aprendizagem numa lógica do conhecer, como processo individual, mas também do fazer e do ser, de modo a garantir um desenvolvimento pessoal e social mediado pela cultura como sistema convencional simbólico; por conseguinte, a aprendizagem tem assim, uma natureza contextual e, portanto, pode ser potenciada, por meio de experiências educativas significativas diversas e diversificadas, princípio básico para alicerçar a formulação de programas de educação mais amplos e, consequentemente, uma política educativa mais articulada e inovadora.

Mais do que optar por qualquer uma das correntes pedagógicas, polarizadas em torno do indivíduo, sociedade e conhecimentos, devemos considerar que qualquer política de educação que não considere as pessoas na sua singularidade e autonomia, não contemple a necessidade de encarar a transformação da sociedade tanto do ponto de vista das condições materiais como de justiça social e não se preocupe com a disseminação do conhecimento, não está a contribuir para melhorar as condições de vida da população e o desenvolvimento do país.

Uma aprendizagem significativa exige compreensão da informação de modo a poder ser aplicada em situações diferentes. Ela é condição de ação consciente e consistente. Ela é importante na elaboração de novas possibilidades de saber e de organização. 
As pessoas, as comunidades e o saber têm de ser relacionados num pensamento que supere dicotomias ou radicalizações que atentem contra a harmonia da educação. A hipervalorização de um dos vértices em detrimento dos outros vai prejudicar a qualidade da educação e o desenvolvimento da sociedade. Há que se garantir que a educação seja pensada de modo que as aprendizagens sejam significativas. Só essas poderão propiciar maior ligação entre pensamento e ação, entre retórica e prática, entre ideologia e política. Elas resultam da apropriação de informação num quadro de leitura de mundo condicionado pela compreensão da sociedade. O saber das pessoas não advém só delas e não é só para elas. Ele resulta de processos psicognitivos e sociocognitivos.

A educação deve visar à realização das pessoas, mas essas não são indiferentes à sorte da sociedade. Por sua vez, a sociedade é demasiado fragmentada social e culturalmente, é composta de diversificados grupos como uma justaposição de mosaicos de materiais, cores e texturas. Nesse sentido, a educação não pode ignorar a heterogeneidade das pessoas, a diversidade dos projetos de vida, as suas condições e capacidades. Seja como for, pensamos que a realização das pessoas passa por uma sociedade equitativa, justa, inclusiva e capaz de valorizar a ampliação do conhecimento como necessária ao bem-estar de cada um. Mas tudo isto tem de passar, também, por uma educação integral que valorize a totalidade da pessoa e atenda ao seu desenvolvimento físico, intelectual e social. Uma sociedade sendo composta de pessoas depende das suas características, das suas qualidades, da sua formação.

\section{FORMAÇÃO DOCENTE}

No decorrer das últimas décadas do século $\mathrm{XX}$, as mudanças culturais, socioeconômicas e sistemas tecnológicos em plena desenvoltura criaram necessidades formativas cada vez maiores para poderem, no universo globalizado, atuarem de maneira convincente, nas quais a demanda pelo conhecimento se mostraram fator preponderante para inclusão do indivíduo no mundo laboral, no mundo da velocidade da informação, delegando à formação superior a responsabilidade pelo necessário desenvolvimento cultural e econômico. Essas mudanças significativas nos critérios de ensino passam a incitar o aluno para a procura do conhecimento, através de pesquisa e experimentos, beneficiando a evolução de criatividade e raciocínio crítico. As metodologias de ensino passam a ser ativas e participativas, fazendo com que os alunos 
desenvolvam competências pessoais de autonomia, de como aprender a fazer e aprender a pensar, de resolução de problemas e de elaboração de projetos, ou seja, passam a ter, em seu centro, o aluno e os objetivos que permeiam sua formação, deixando o caráter convencional de aulas presenciais, nas quais a passividade desses atores era patente, para ações direcionadas à prática, ao uso de laboratórios e trabalhos de campo.

Em estudos efetuados por Bidarra et al. (2014), numa amostra de 990 professores e de 4568 estudantes de quatro universidades portuguesas, fica evidenciado que, enquanto na percepção dos estudantes está ainda muito presente o paradigma tradicional de ensino expositivo com avaliação final por teste e exame, na percepção dos professores, parece existir uma mudança de paradigma, com o recurso das metodologias mais ativas. Por outro lado, num estudo efetuado por Rodrigues e Soromenho (2015), com base na mesma amostra, é possível verificar algumas diferenças em relação às áreas de conhecimento. Assim, o paradigma mais centrado no estudante parece estar a operar-se mais nos cursos de artes e humanidades e de ciências sociais do que nos cursos de ciências e tecnologias e ciências da saúde.

Outro aspecto a considerar é o desenvolvimento das Tecnologias de Informação e Comunicação (TIC's), que auxiliaram alunos e docentes a ingressarem num mundo integrado, seja economicamente, seja por valores e posturas. A informação chega incontinenti e mutável rapidamente e a visão segmentada estabelecida pelo padrão fordista, em qualquer área, já não se adequa mais como modelo referencial porquanto que, cada vez mais, as peculiaridades de cada atividade precisam dar lugar ao conhecimento mais abrangente, com técnicas mais contextualizadas, integradas no princípio da globalização, mormente ao se falar em docência.

A escola se apresentando como espaço educacional faz surgir necessidades de desenvolvimento de competências diferentes dos professores face às exigências inovadoras da profissão docente, que, diante dos problemas presentes, crie possibilidades de rastrear uma escola real, culminando com uma também diferente perspectiva de ser professor (NÓVOA 2002). E que, além disso, essa transformação da escola em ambiente educacional, na qual trabalho e formação não sejam movimentos diversos, traga e confira aos professores uma contribuição inconteste para solução de contratempos no universo escolar. 
Fator importante a ser considerado, dentro da visão construtivista, é que os alunos, via de regra, retém, com maior propriedade, os saberes mediante situações de aprendizagem desenvolvidas através de atividades e outras técnicas orientadas, em que a mescla de informações teóricas são brindadas com situações de aplicação reais.

Nesse contexto, as estratégias formativas qualificam e potencializam os envolvidos nesse processo. Para que o professor seja criativo e capaz de fazer um ensino adequado, que ultrapasse a mera reprodução de conhecimentos, torna-se necessária uma formação que o habilite para tal, com métodos novos, baseados nas descobertas científicas da pedagogia moderna.

\section{DOCÊNCIA: DESAFIOS E COMPETÊNCIAS}

A preocupação com a docência, seja nos anos iniciais de aprendizado do aluno, seja em nível universitário, tem levado outros autores como Garcia (1992, 1999), Anastasiou; Alves (2004) e Perrenoud (2000; 2002), a procurarem identificar quais as competências os professores precisam possuir para exercer sua atividade docente, adaptados à realidade de seu tempo e às necessidades dos alunos e instituições. Assim, diversos autores têm proposto concepções de competências docentes, identificando quais e como devem ser encaradas essas novas funções da docência, suas características e o que fazer para desenvolvê-las já que precisam ser trabalhadas como qualquer outra habilidade da docência.

Nesse contexto, podem referir-se as competências para a docência mencionadas por Perrenoud (2000): organizar e dirigir situações de aprendizagem; administrar a progressão das aprendizagens; conceber e fazer evoluir os dispositivos de diferenciação; envolver os alunos em suas aprendizagens e em seu trabalho; trabalhar em equipe; participar da administração da escola; informar e envolver os pais; utilizar novas tecnologias; enfrentar os deveres e os dilemas éticos da profissão e, por último, administrar sua própria formação continuada.

O Quadro 1 apresenta um resumo das competências delineadas por Perrenoud (2002), bem como algumas ações propostas que com certeza facilitam e podem levar ao desenvolvimento dessas competências. 
Quadro 1-Competências docentes na perspectiva de Perrenoud (2002)

\begin{tabular}{|c|c|}
\hline COMPETÊNCIAS & AÇÕES PARA O SEU DESENVOLVIMENTO \\
\hline Organizar e dirigir & $\begin{array}{l}\text { - Saber construir e planejar dispositivos e sequências didáticas; } \\
\text { - Envolver os alunos em atividades de pesquisa; } \\
\text { - Saber considerar os erros e os obstáculos da aprendizagem; } \\
\text { - Saber selecionar conteúdos. }\end{array}$ \\
\hline $\begin{array}{l}\text { Administrar aprogressão das } \\
\text { aprendizagens }\end{array}$ & $\begin{array}{l}\text { - Observar e avaliar os alunos, levando em conta suas } \\
\text { particularidades; } \\
\text { - Administrar os problemas de acordo com as características e } \\
\text { possibilidades dos alunos; } \\
\text { - Acompanhar as e tomar decisões de progressão; } \\
\text { - Relacionar as teorias subjacentes às atividades de } \\
\text { aprendizagem. }\end{array}$ \\
\hline $\begin{array}{l}\text { Conceber e evoluir } \\
\text { osdispositivos } \\
\text { dediferenciação. }\end{array}$ & $\begin{array}{l}\text { - Fazer desenvolver a cooperação entre os alunos; } \\
\text { - Saber trabalhar a heterogeneidade; } \\
\text { - Fornecer apoio integrado. }\end{array}$ \\
\hline Envolver os alunos & $\begin{array}{l}\text { - Desenvolver no aluno a vontade de aprender e a ele se dedicar; } \\
\text { - Disponibilizar estratégias diferenciadas; } \\
\text { - Saber mostrar aos alunos que eles são peças importantes no } \\
\text { seu próprio desenvolvimento. }\end{array}$ \\
\hline Trabalhar em equipe & $\begin{array}{l}\text { - Saber desenvolver nos alunos a ideia de equipe; } \\
\text { - Saber trabalhar com os alunos a ideia de equipe; } \\
\text { - Trabalhar em equipe com os alunos. }\end{array}$ \\
\hline $\begin{array}{l}\text { Participar daadministração da } \\
\text { escola }\end{array}$ & $\begin{array}{l}\text { - Participação das reuniões pedagógicas e administrativa; } \\
\text { - Sentir-se co-responsável pelos caminhos que a instituição } \\
\text { segue e pretendeseguir. }\end{array}$ \\
\hline $\begin{array}{l}\text { Administrar sua formação } \\
\text { contínua }\end{array}$ & $\begin{array}{l}\text { Conscientizar-se da necessidade de seu desenvolvimento } \\
\text { profissional; } \\
\text { - Procurar cursos de formação continuada; } \\
\text {-Trocar experiências com seus pares. }\end{array}$ \\
\hline Utilizar novas tecnologias & $\begin{array}{l}\text { - Ensinar os alunos a trabalhar com o computador; } \\
\text { - Utilizar os recursos tecnológicos em sala de aula; } \\
\text { - Propor desafios usando os recursos tecnológicos }\end{array}$ \\
\hline $\begin{array}{l}\text { Enfrentar os deveres e os } \\
\text { dilemas éticos da } \\
\text { profissão }\end{array}$ & $\begin{array}{l}\text { - Combater todas as formas de segregação e preconceito; } \\
\text { - Combater a violência dentro da sala de aula; } \\
\text { - Participar da criação de regras de conduta quanto à } \\
\text { disciplina; } \\
\text { - Saber desenvolver nos alunos a consciência de justiça e } \\
\text { solidariedade. }\end{array}$ \\
\hline $\begin{array}{l}\text { Informar e envolver os } \\
\text { pais }\end{array}$ & $\begin{array}{l}\text { - Estar em contato com os responsáveis pelo aluno; } \\
\text { - Dar conhecimento aos responsáveis do desenvolvimento } \\
\text { dos alunos. }\end{array}$ \\
\hline
\end{tabular}

Fonte: Elaboração própria.

Como podemos perceber, a formação de professores vem, já há tempo, sendo estudada e contemplada com inúmeros trabalhos científicos. Atualmente, são diversos 
os paradigmas que enfocam a formação de professores, que remetem para diferentes concepções de docência subjacentes, incluindo também o entendimento da formação inicial e da formação continuada que oraprivilegia esta ou aquela formação.

Três modelos são estabelecidos Ferry (1987): centrado nas aquisições, centrado no processo e centrado na análise. O primeiro deles tem como característica ser uma ação anterior a ser professor, com vista à aquisição e ao aprimoramento de competências tendo em mente os resultados. $\mathrm{O}$ segundo, focando as práticas, tem em vista mais o processo do que os contributos dele advindos, entendendo o professor como uma pessoa capacitada a agir e reagir às conjunturas eventuais e manifestamente complicadas em sala de aula. O terceiro, centrado na análise, dá maior ênfase aos cenários pedagógicos provenientes do trabalho, concebendo a formação como preocupada com o professor enquanto profissional tendo como base as práticas de sala de aula.

Com apresentação de quatro paradigmas na concepção de formação de professores, Eraut (1995) nomeia-os como paradigmas da compensação de deficit, do desenvolvimento, da mudança e da resolução de problemas. Como o nome sugere, o primeiro paradigma, da compensação de deficit, enfoca a formação com a visão de que o professor precisa ser constantemente atualizado. A formação continuada está compreendida dentro do paradigma do desenvolvimento, como um processo contínuo, seja qual for o sistema de formação profissional.

O paradigma da mudança implica o apuramento das alterações implementadas pelos diversos programas de educação e de ensino, que têm de acompanhar efetivamente as mudanças sociais e tendo a referência de que, aos professores, é necessário o acompanhamento para harmonizar-se com as novas transformações. Por fim, o paradigma da resolução dos problemas que se baseia na superação de dificuldades em certas situações, tendo como base as necessidade das instituições e as ações em sala de aula (ERAUT, 1995). Também Garcia (1999) apresenta quatro paradigmas na formação de professores: o tradicional, que conserva a dissociação entre prática e teoria; o personalista, que dá maior destaque à natureza individual do ensino; $\mathrm{o}$ condutista, que concede valor ao professor enquanto técnico e o direciona à investigação como opção aos demais já enunciados. Essa perspectiva nos remete para os 
paradigmas propostos por Zeichner (1983), contendo três paradigmas igualmente referenciados por Garcia (1999).

Zeichner (1983) propôs quatro distintos paradigmas na formação de professores, baseados no grau de estruturação e nos contextos institucionais e sociais. Assim, o paradigma tradicional, no qual o professor encara os alunos como receptores passivos, baseia-se no transmitir do conhecimento que se vai alicerçando com os saberes adquiridos na prática, não tendo a formação pedagógica maior relevância. O paradigma comportamentalista reporta-se ao princípio do século XX e tem sido dominante nos estudos de formação de professores, orientando-se para solução de problemas, caracterizada pela relevância do desenvolver das capacidades de ensino com objetivos determinados, sendo o professor considerado como um mero executor de tarefas. $\mathrm{O}$ paradigma personalista tem como foco a figura do professor, desempenhando a formação um contributo para o seu desenvolvimento, alavancando a maturidade do docente na aquisição de competências específicas que não estão prédefinidas.

Por último, o paradigma investigativo ou reflexivo valoriza a investigação e a reflexão a partir dos contextos de aprendizagem, nos quais o professor e o contexto são ímpares, defendendo uma atitude reflexiva e prestigiando, ainda, a conquista de capacidade técnica própria da profíssão como meio de se alcançar os objetivos (ZEICHNER, 1983). Esses paradigmas estão representados no Quadro2.

Quadro 2- Paradigmas de Zeichner no âmbito da formação de professores

\begin{tabular}{|c|c|}
\hline Tradicional & $\begin{array}{l}\text {-o professor se coloca de maneira mais tradicional ao ensinar; } \\
\text { - baseia-se no transmitir do conhecimento que vai se alicerçando com os } \\
\text { saberes adquiridos e a prática; } \\
\text { - a formação pedagógica menor relevância; } \\
\text {-os professores vistos como receptores passivos. }\end{array}$ \\
\hline Comportamentalista & $\begin{array}{l}\text { - se reporta ao princípio do século; } \\
\text { - é dominante nos estudos de formação de professores; } \\
\text { - se orienta para solução de problemas, caracterizado pela relevância do } \\
\text { desenvolver das capacidades de ensino com objetivos determinados, } \\
\text { - professor é simples executor de tarefas. }\end{array}$ \\
\hline Personalista & $\begin{array}{l}\text { - tem como foco a figura do professor; } \\
\text { - a formação contribui para seu desenvolvimento e promove sua maturidade; } \\
\text { - coloca como eixo o adquirir de competências específicas do conhecimento } \\
\text { e não pré-definidos. }\end{array}$ \\
\hline $\begin{array}{l}\text { Investigativo } \quad \text { ou } \\
\text { reflexivo }\end{array}$ & $\begin{array}{l}\text { - valorizada a investigação e a reflexão a partir dos contextos de processos } \\
\text { de aprendizagem; } \\
\text { - defende uma atitude reflexiva dos professores, }\end{array}$ \\
\hline
\end{tabular}




\begin{tabular}{|l|l|}
\hline & $\begin{array}{l}\text {-prestigia a conquista de capacidade técnica própria da profissão como meio } \\
\text { de se alcançar os objetivos indicados; } \\
\text { - professores e contextos são ímpares. }\end{array}$ \\
\hline
\end{tabular}

Fonte: Elaboração própria.

de se alcançar os objetivos indicados;

Entender o que é reflexão passa a ser, indubitavelmente, uma questão importante para compreender sua aplicabilidade no ensino. Na opinião de vários autores, como Schön (2000), ela permite que a entendamos como formação diferenciada do lugar comum, que remete o professor a um simples técnico que cumpre orientações que lhe são passadas.

O ensino reflexivo, dentro da perspectiva de Zeichner (1993), não é limitado ao modo como os docentes ministram as teorias aprendidas, mas como refletem sobre essas teorias e como percebem suas práticas docentes. É muito comum ouvir-se dos alunos, sejam eles de cursos médios ou cursos profissionalizantes, que estão ali para obter um diploma que os dirija ao mundo laboral mais rapidamente, sem sequer saber o que os espera realmente e o que lhes será exigido como profissionais. Uma das funções dos professores é estimulá-los à prática da reflexão, sobre o que eles pretendem para si mesmos como pessoas e futuros profissionais. A responsabilidade pelo pouco interesse que os alunos demonstram por não estarem preparados para pensarem, analisarem e refletirem sobre o andar de suas vidas e de suas escolhas para o que poderá vir a ser, em última análise, é das escolas e dos professores que são fundamentais na influência direta dos alunos.

\section{CONCLUSÃO}

A educação é a grande fonte de desenvolvimento pessoal, social e cultural e a escola e os professores peças fundamentais nesta engrenagem e, por assim serem, há que se pensar na escola enquanto campo fértil para o desenvolvimento da prática reflexiva, tanto para seus docentes, como para os alunos. A escola, enquanto organização, deve pensar em si mesma com frequência, podendo tornar-se responsável e educadora. As constantes e as aceleradas mudanças a que o mundo está sujeito determinam atualização constante de todas as instituições, devendo ser fortificada a possibilidade de a educação, a escola e seus docentes serem os atores principais de seu próprio crescimento individual e coletivo. 
Portanto, para que o professor seja criativo e capaz de fazer um ensino adequado que ultrapasse a mera reprodução de conhecimentos, torna-se necessária uma formação que o habilite para tal, com métodos novos, baseados nas descobertas científicas da pedagogia moderna (FERREIRA; MOTA, 2010). Uma formação que colabore com a profissionalização da educação, que forme professores e também pensadores, profissionais intelectuais que possam colaborar com o processo educativo dentro e fora da sala de aula na promoção de uma educação integral e emancipadora. Para isso, é importante garantir uma educação integral também para os professores, na formação inicial e continuada, de forma que sustente não somente o discurso, mas a sua prática docente.

Há tempos que a escola dá indícios de mudanças necessárias à sua reconfiguração. Na docência, percebemos o anseio por mudanças no discurso dos profissionais. A reprodução de velhos costumes depara-se com os novos modelos, distanciando, por vezes, o discurso da prática, seja pela forma como as políticas são implementadas, seja pela carência de formação e conhecimentos necessários para construir e desenvolver projetos e programas. Nesse cenário, muito se pode fazer pelo desenvolvimento cognitivo do estudante, investindo em atividades que os levem a permanecerem na escola ou a envolverem-se em situações de resolução de problemas, ainda que isso possa não se traduzir em resultados escolares imediatos.

\section{REFERÊNCIAS}

ANASTASIOU, L. C. Ensinar, aprender, apreender e processos de ensinagem. Joinville: UNIVILLE , 2004.

ANASTASIOU , L.G. C; ALVES, L. P. (Orgs.). Processos de ensinagem na universidade:

pressupostos para as estratégias de trabalho em aula. Joinville: UNIVILLE, 2004.

ARENDT, H. A condição humana. 10. ed. Rio de Janeiro: Forense Universitária. 2007.

BERTRAND, Y. Teorias contemporâneas da educação. 2.ed, Lisboa Portugal: Instituto Piaget, 2001.

BERTRAND, Y.; VALOIS, P. Paradigmas educacionais: escola e sociedades. Lisboa: Instituto Piaget.1994. 
BIDARRA, M. G. et al. Percepções de docentes e estudantes face à avaliação das aprendizagens no ensino superior: análises preliminares das respostas ao questionário AVENA. In: MEMBIELA, P.; CASADO, N.; CEBREIROS, M.I (Eds.). Investigaciones en el contexto universitario actual / investigacións no contexto universitario actual. Ourense: Educación Editora. 2014. pp. 727-730.

BOBBIO, N. O futuro da democracia. Lisboa: Publicações Dom Quixote. 1988.

DENNICK, R. Theories of learning: constructive experience. In: D. Matheson. (ed.) Na introduction to the study of education New York: Routledge. Piaget, J. (1970). Structuralism. New York: Basic Books. p 36-63, 2015.

DEWEY, J. Democracy and e educacion. New York: Dover Publitions. Inc., 2004. ERAUT, M. Developing professional knowledge and competence. Londres: The Falmer Press.1995.

FERREIRA, A. G. A difusão da escola e a afirmação da sociedade burguesa. Revista Brasileira de História da Educação, 9 jan./jun. 2005. Disponível em: http://www.rbhe.sbhe.org.br/index.php/rbhe/article/view/185/193

FERREIRA, A. G.; MOTA, L. A formação de professores do ensino secundário em Portugal no século $X$. Revista de Educação PUC-Campinas, v. 18, n.1, p.115-123, 2013.

FERRY, G. Le trajet de la formation. Paris: Bordas/Dunod. 1987.

GARCÍA, C. M. Formação de professores: para uma mudança educativa. Porto: Porto Editora, 1999.

HANSOTTE, M. As inteligências cidadãs: como se adquire e inventa a palavra coletiva.Lisboa: Instituto Piaget, 2005.

NÓVOA, A. Formação contínua de professores: realidades e perspectivas. Aveiro: Universidade de Aveiro, 2002.

PERRENOUD, P. Dez novas competências para ensinar. Porto Alegre: Armed. 2000.

PERRENOUD, P. A prática reflexiva no ofício de professor: profissionalização e razão pedagógica. Porto Alegre: Armed, 2002.

UNDP. Human development report 2015 team. United Nations Development Programme, New York, USA. 2015.

VIGOSTSKY, L. S. El desarrollo de los procesos psicológicos superiores. Barcelona: Crítica, 1979.

PIAGET, J. Para onde vai à educação? Rio de Janeiro: José Olímpio, 2007. 
UNESCO. Educação para a cidadania global: tópicos e objetivos de aprendizagem. Brasília: UNESCO. 2016. Disponível em:

file:///C:/Users/global1/Downloads/244826POR(4).pdf

ZEICHNER, K. Alternative paradigms of teacher Educations. Journal of Teacher Education, v. 34, n.3, 1-9., 1983. 